\title{
Methods to determine wood moisture content and their applicability in monitoring concepts
}

\author{
Philipp Dietsch \\ Dr.-Ing., Research Associate \\ Chair of Timber Structures and Building Construction \\ Technische Universität München, Germany \\ Steffen Franke \\ Prof. Dr.-Ing, Professor for Timber Constructions \\ Bern University of Applied Sciences, \\ Architecture, Wood and Civil Engineering \\ CH-2504 Biel/Bienne, Switzerland \\ Bettina Franke \\ Dr. Ing., Research Associate \\ Bern University of Applied Sciences, \\ Architecture, Wood and Civil Engineering \\ CH-2504 Biel/Bienne, Switzerland \\ Andreas Gamper \\ MSc, Research Assistant \\ Chair of Timber Structures and Building Construction \\ Technische Universität München, Germany \\ Stefan Winter \\ Univ.-Prof. Dr.-Ing. \\ Chair of Timber Structures and Building Construction \\ Technische Universität München, Germany
}

\begin{abstract}
The reaction of wood to moisture forms an integral part of any task in connection with this natural and renewable building material. Changes in wood moisture content lead to changes of virtually all physical and mechanical properties (e.g. strength and stiffness properties) of wood. Another effect of changes of the wood moisture content is the associated shrinkage or swelling of the material. The existence of high moisture content can initiate decay or growth of fungi. The correct estimation of timber moisture content and the subsequent initiation of potentially necessary measures are therefore essential tasks during the planning, execution and maintenance of buildings built with wood or woodbased products. This is supported by the high amount of damages on structural timber elements that can be attributed to ignorance of the reaction of wood to moisture. Also supported by this fact, the in-situ monitoring of moisture content of structural timber elements has recently received considerable interest and growth. This paper describes common methods to determine wood moisture content and evaluates them with respect to their applicability for monitoring concepts.
\end{abstract}


Keywords: wood; moisture; measurement; monitoring; temperature; relative humidity; moisture gradients; shrinkage; swelling

\section{Wood and its reaction to moisture}

Wood is characterized by its hygroscopic nature. Like all porous materials, this enables wood to take in water from the air and store it within the cell membrane and cell cavities. The hygroscopic behavior of wood describes the adsorption and desorption of moisture to maintain equilibrium depending on the surrounding climate in particular relative humidity and temperature. As shown in Fig. 1, the adsorption of moisture occurs in two steps in the range from $0 \%$ to approx. $30 \%$ where the moisture is transferred into the cell walls of the wood. Above the so-called fibre-saturation point, the cell walls are completely saturated and the moisture is transferred into the cavities of the cells. The fiber saturation point varies depending on the wood species (e.g. oak, ash: 22-24\%, pine, larch, douglas-fir: 26$28 \%$, fir, spruce: $30-34 \%$, oak, ash: $32-35 \%$ [1]. Changes in the moisture content below the fiber saturation point affect the physical, mechanical and rheological properties of wood, like shrinking and swelling, the strength values or the modulus of elasticity or rigidity, see e.g. [1] - [4] and Fig. 2. In standards for the design of timber structures, e.g. EN 1995-1-1 [5], this is accounted for by classifying the timber elements into one of three possible service classes according to the expected climatic conditions during the design service life.

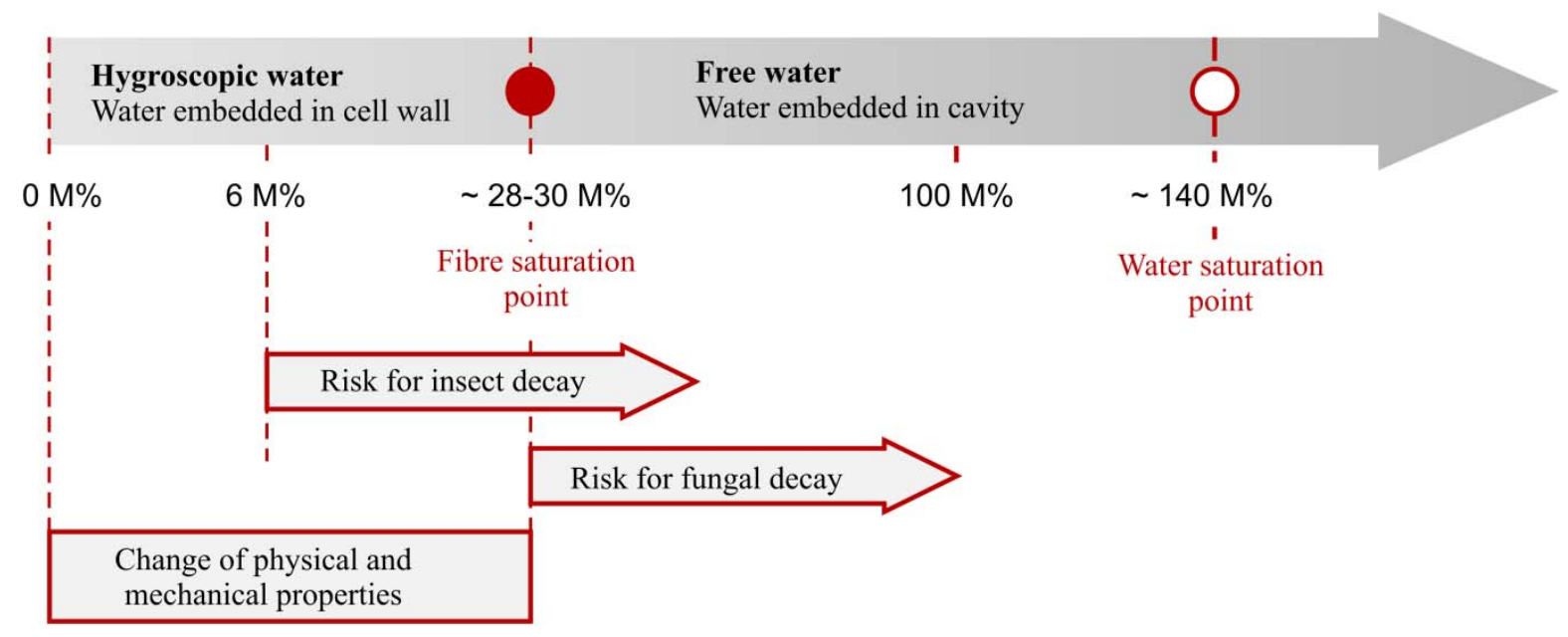

Fig. 1: Range of wood moisture content and influence on its properties and vulnerability 


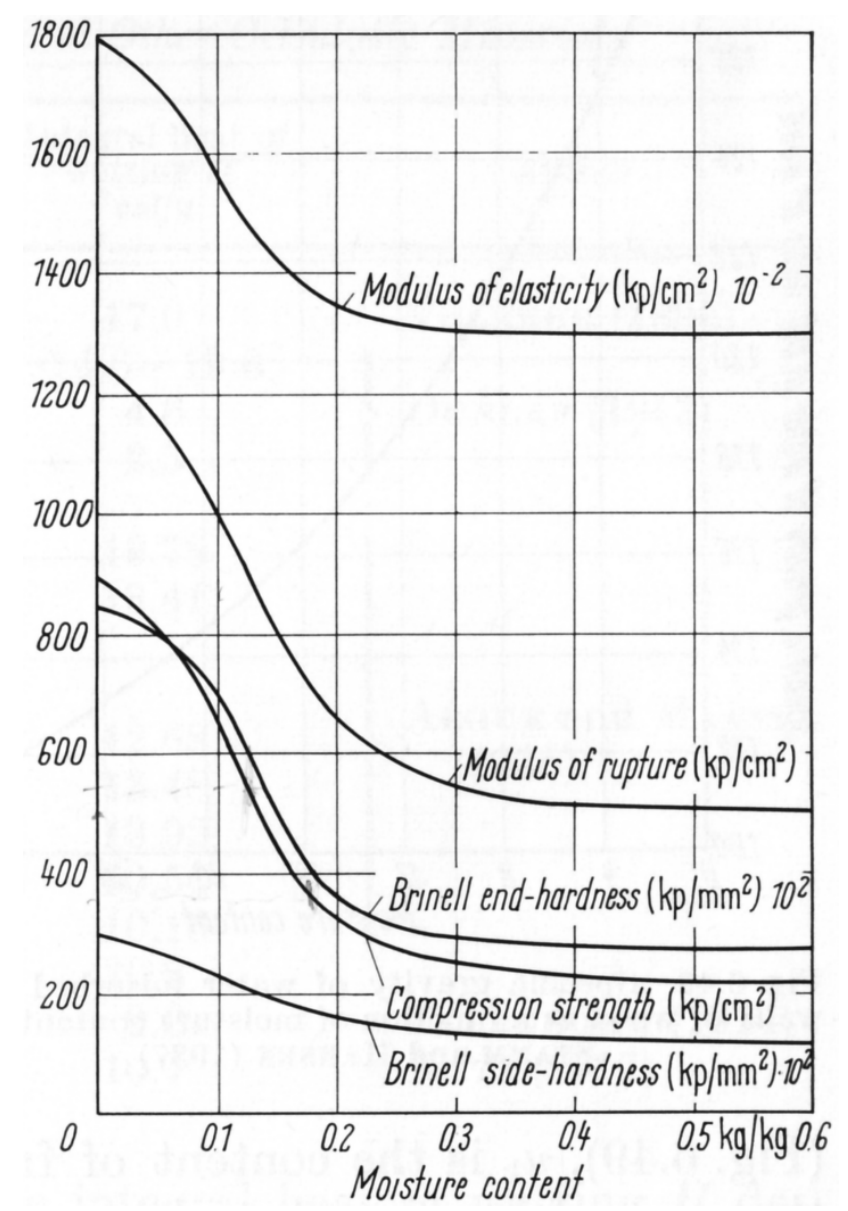

Fig. 2: Influence of wood moisture content on selected wood properties, from [1]

The dimensional changes of wood due to changes in moisture content (shrinkage, swelling) are different in the three material axes (longitudinal, tangential or radial). Shrinkage and swelling are significantly more pronounced in radial and tangential direction than in longitudinal direction as sketched in Fig. 3. Below the fiber-saturation point, water is transported primarily through diffusion in and out of the surface of the wood. Since the outermost sections of the wood cross-sections will adapt to the climatic conditions at first, the resulting moisture gradient and the associated shrinkage or swelling will lead to equilibrium of internal compression and tension perpendicular to the grain stresses in the cross-section. Although these stresses are partly reduced over time by relaxation processes, an excess of the tension perpendicular to the grain strength results in instant stress relief in form of cracks, see Fig. 4. The most common reason for cracks in structural timber elements is changing surrounding climate. 


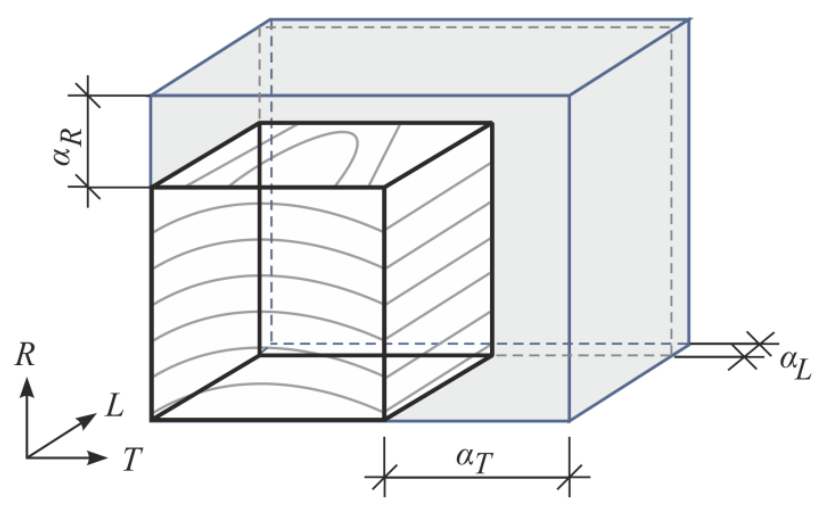

Fig. 3: Shrinkage or swelling depending on the material direction

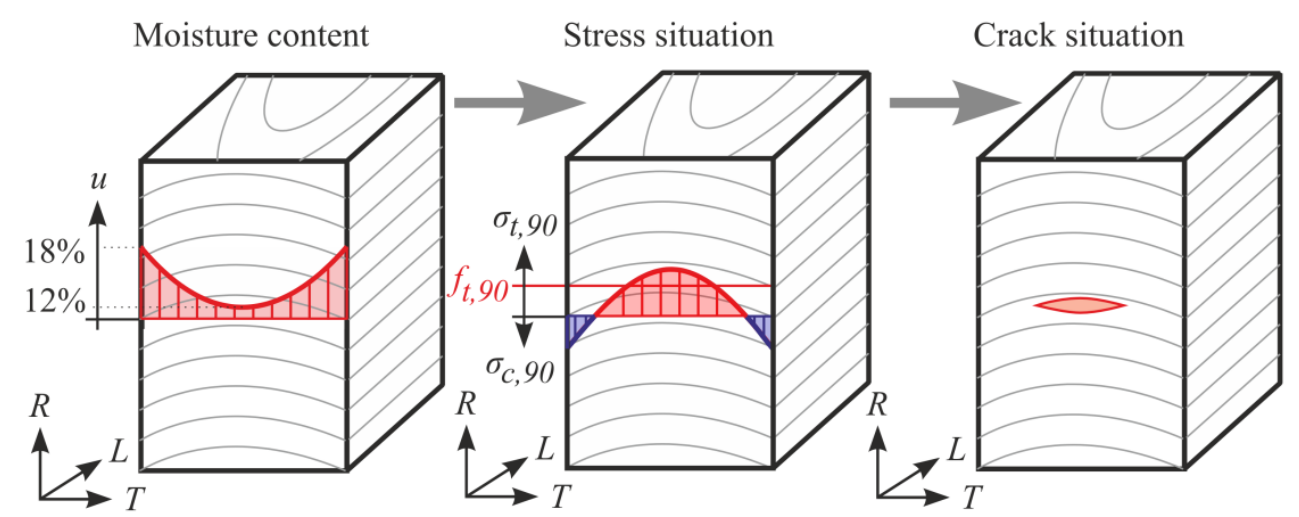

Fig. 4: Example of moisture gradient, corresponding internal stresses and potential internal crack growth

When stored in constant climate, wood reaches the so-called equilibrium moisture content which is influenced by the relative humidity, temperature, air pressure and chemical and structural composition of the wood. The relationship between these factors and the equilibrium moisture content of wood is often represented by sorption isotherms, see Fig. 5. Fig. 5 also shows that structural timber elements will in most cases feature moisture contents below the fiber-saturation point. Since the speed of the water intake is generally higher than the speed of water release, the typical $S$ shaped sorption isotherms for adsorption and desorption are not identical but form a hysteresis, see Fig. 6. 


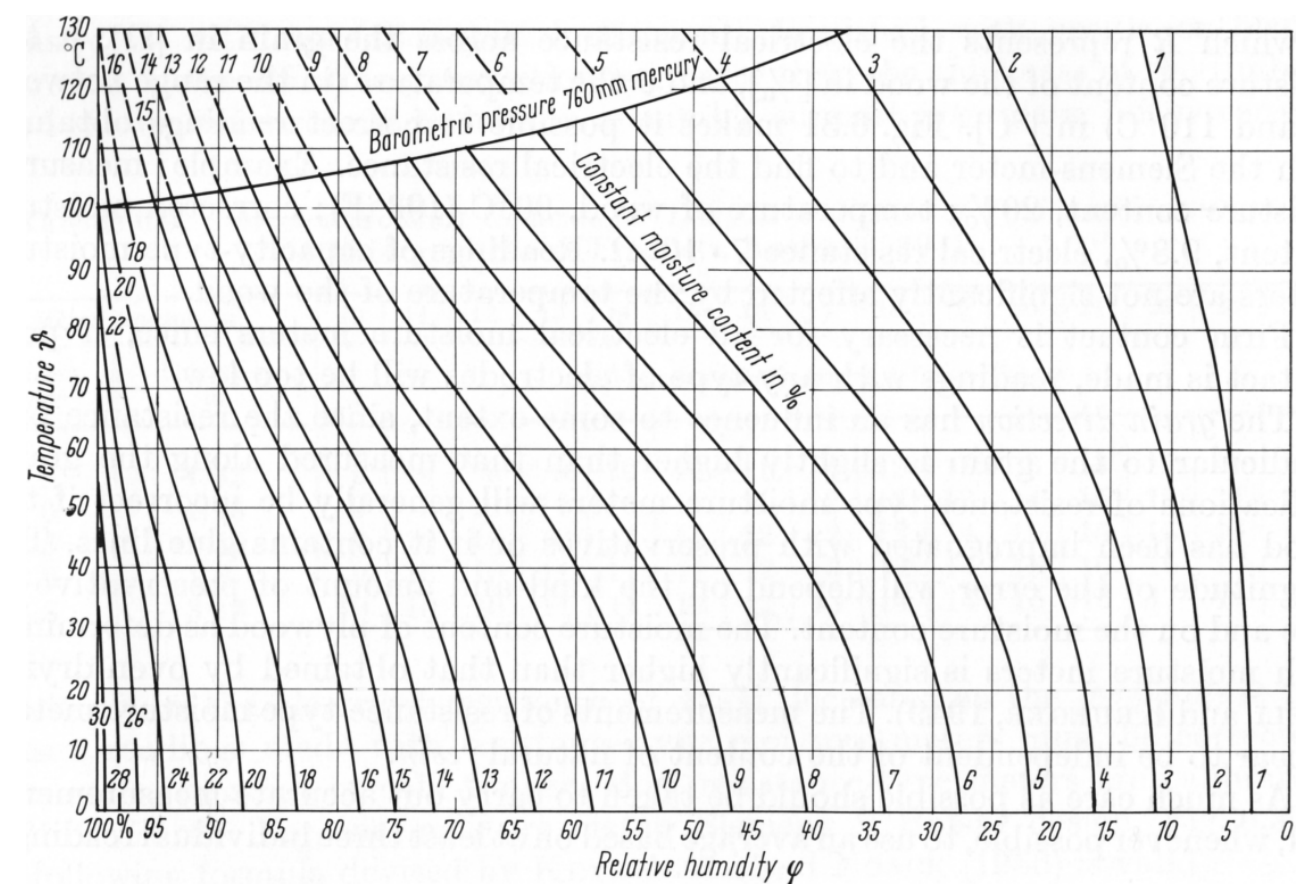

Fig. 5: Equilibrium moisture content of Sitka spruce in relationship to temperature and relative humidity, from [6] worked out by Loughboroug, converted, corrected and extrapolated by [7], printed in [1]

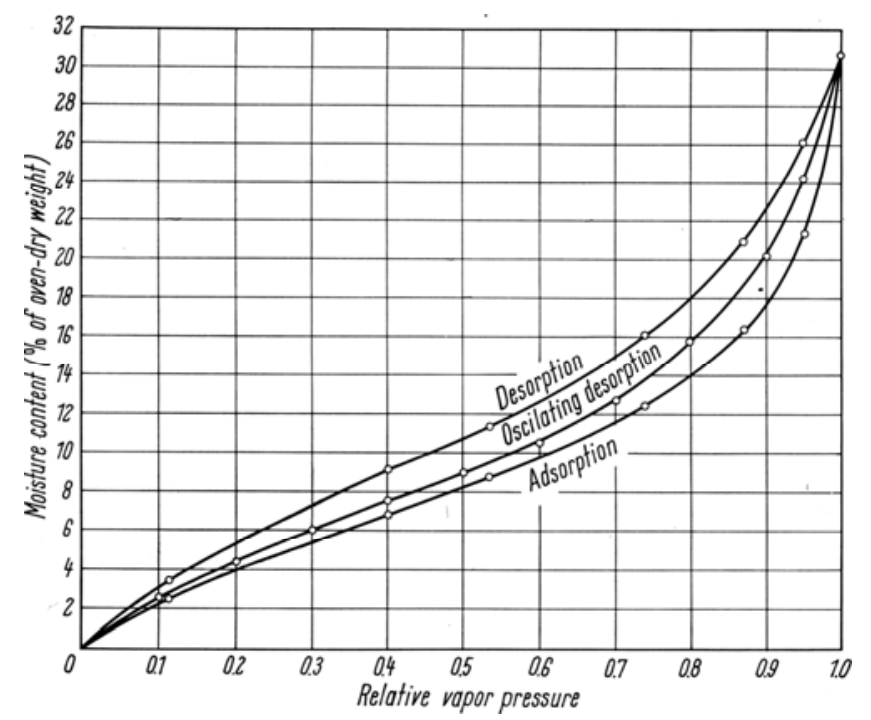

Fig. 6: Sorption isotherm and bonding forms of water, from [8], printed in [1]. Relative humidity $=$ relative vapour pressure $\cdot 100$

\section{Methods to determine the wood moisture content}

Two general approaches to determine wood moisture content can be distinguished. In direct measurements, the moisture content is determined by oven-drying or water extraction, whereby both are destructive methods with respect to timber members in-situ. Indirect measurement methods use physical properties of wood which are correlated to the wood moisture content. See Fig. 7 for an overview of available methods. 


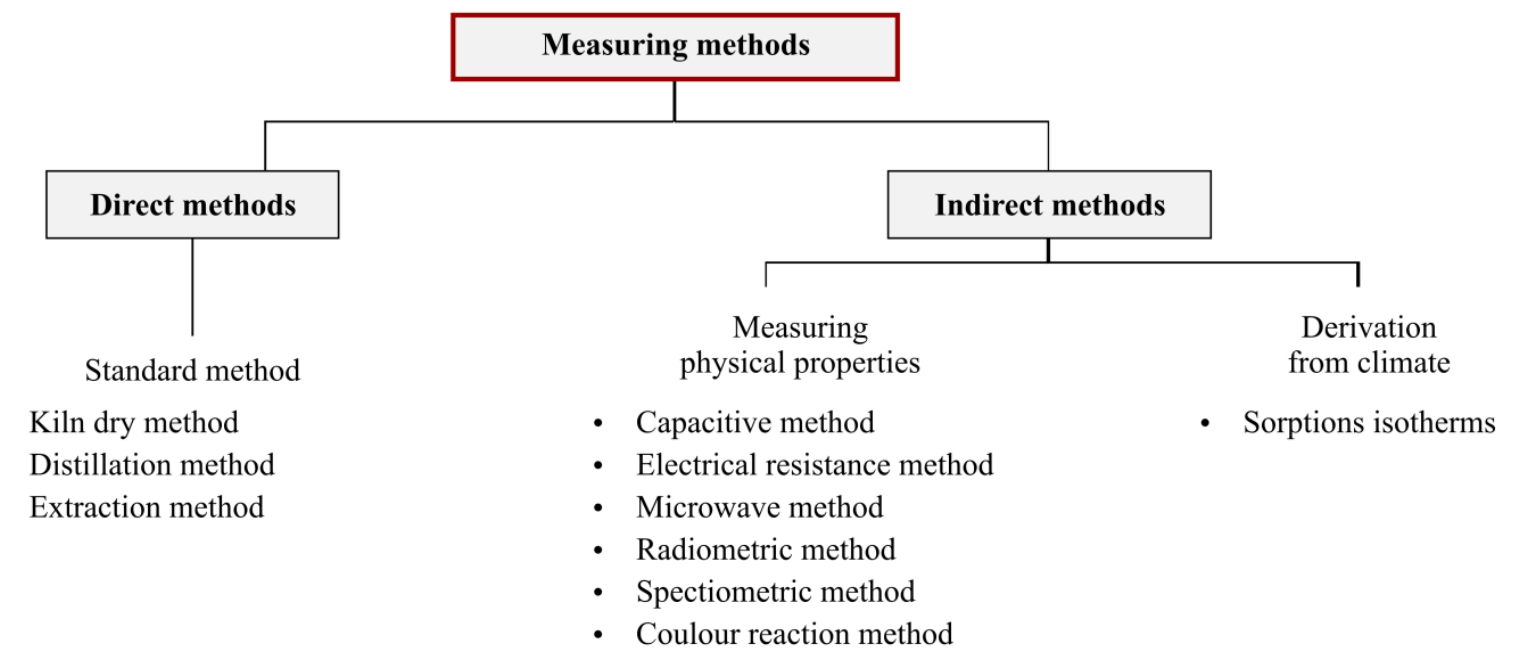

Fig. 7: Overview of the methods to determine wood moisture content

\subsection{Direct methods to determine the wood moisture content}

\section{Oven-drying method}

This gravimetric method is amongst the most widely-used and oldest methods to determine wood moisture content. It necessitates the extraction of specimen from the timber element. These are weighed before kiln-drying them at a temperature of $103{ }^{\circ} \mathrm{C} \pm 2 \mathrm{~K}$ until constant mass is achieved. The moisture content $u$ is determined from the ratio between the mass of water in the moist specimen $\left(m_{\mathrm{u}}-m_{\mathrm{dr}}\right)$ and the mass of the kiln-dried specimen $\left(m_{\mathrm{dr}}\right)$. The method is standardized, see [9].

The kiln-dry method delivers very exact results which are e.g. used to calibrate measurement equipment. However it is a destructive method since it necessitates the extraction of specimen and its application is rather time-consuming. The method of extraction must be choosen carefully acoording to the local situation. The drilling process during core extraction may lead to vapour evaporation due to the temperature increase, leading to a potential corruption of subsequently determined wood moisture content.

Investigations on the moisture gradient in timber elements are possible but difficult since this necessitates the extraction and segmentation of specimen without influencing the moisture content. Since this method is not suitable for in situ measurements, it is not applicable for monitoring concepts.

\section{Distillation method / extraction method}

The oven-drying method is replaced by the distillation method when a sample of wood contains terpens, oils or preservatives. To determine the moisture content, the specimen is chipped, pooled to a sample of 20 to 50 grams and subsequently placed in a flask which is heated and a solvent, e.g. xylene or toluene is added. The water contained in the chips evaporates and ascends. The water vapour then condenses in a cooler on the side of the flask and is collected in a pipe from which the reading can be taken [1], [2]. Since this method involves chipping the wood material, i.e. destruction of parts of timber elements, it is not applicable for monitoring concepts. 


\subsection{Indirect methods to determine the wood moisture content}

\subsubsection{Resistance method}

This indirect method utilizes the electrical resistance or conductivity properties of wood. Since water has a much higher conductivity than wood, the electrical resistance decreases with increasing moisture content [10]. By knowing the correlation between the two, a direct result for the wood moisture content can be derived. This method delivers an acceptable accuracy of $\pm 1,0 \%$ for wood moisture contents between $6 \%$ and the fibresaturation point. Above the fibre-saturation point, the accuracy decreases considerably. Below $6 \%$, the electrical resistance reaches very high values which are challenging to measure. Another factor influencing the electrical resistance of wood is the material temperature. The resistance decreases with increasing temperature, see Fig. 8. With the help of this figure, measurements of electrical resistance can be used to derive the "indicated moisture content" at $20^{\circ} \mathrm{C}$, i.e. the moisture content which will be displayed by most moisture meters. Knowledge of the indicated moisture content and actual temperature can then be used to derive the actual moisture content at the temperature prevailing around the timber member. Professional moisture meters allow for a direct temperature calibration, see Fig. 11. This necessitates the prior determination of the surface temperature of the timber element, e.g. by contactless infrared temperature meters.

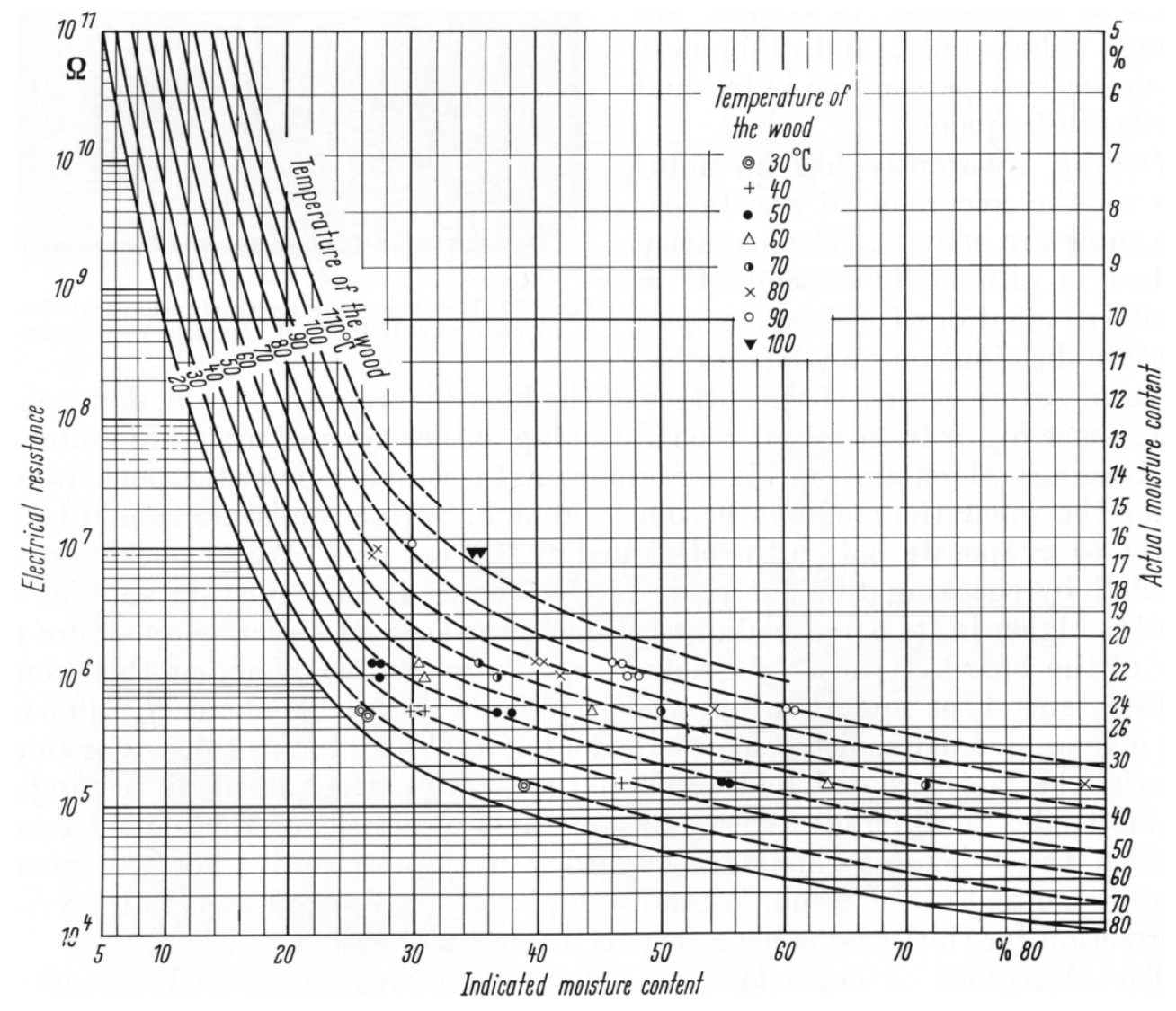

Fig. 8: Influence of moisture content and temperature on the electrical resistance of timber, from [11], printed in [1]

In practice, two electrodes are rammed into the timber or attached to the surface with a defined distance of usually $30 \mathrm{~mm}$ between them, see Fig. 9. It is recommended to orient the two electrodes perpendicular to the grain, i.e. at $90^{\circ}$ since the variation of measured values will be small compared to electrodes placed in grain direction [12], [13]. In case of 
glulam specimen, the electrodes should be placed in the same lamella. The measurement system applies a current to the electrodes and measures the moisture related loss in voltage. This method is commonly applied in practice, e.g. in grading processes. The method is standardized, see [14], and generally applicable for monitoring concepts.

\subsubsection{Dielectric / capacitative method}

Water features pronounced dielectric characteristics in comparison to other materials like wood, i.e. wood changes its dielectric properties in proportion to its moisture content. The dielectric constant increases with increasing moisture content. For measurements, a condensator is placed on the wood surface, the wood acts as dielectric, see Fig. 10. A frequency signal is applied to transmitting electrodes and received by contact electrodes. This method delivers an acceptable accuracy for wood moisture contents from $2 \%$ up to the fibre-saturation point [1], [2]. Material density, material temperature and voltage frequency are the main influences on measurements. The meters do not penetrate the wood material, i.e. only measurements of the average wood moisture content near the surface $(<35 \mathrm{~mm})$ as average are possible; measurement of a moisture gradient is impeded, see Fig. 10. The method is mainly used to measure moisture content of wooden boards, wood based panels or chips, strands respectively flakes. The method is standardized, see [15], and generally applicable for monitoring concepts with abovementioned disadvantages (only surface measurements, no moisture gradient).

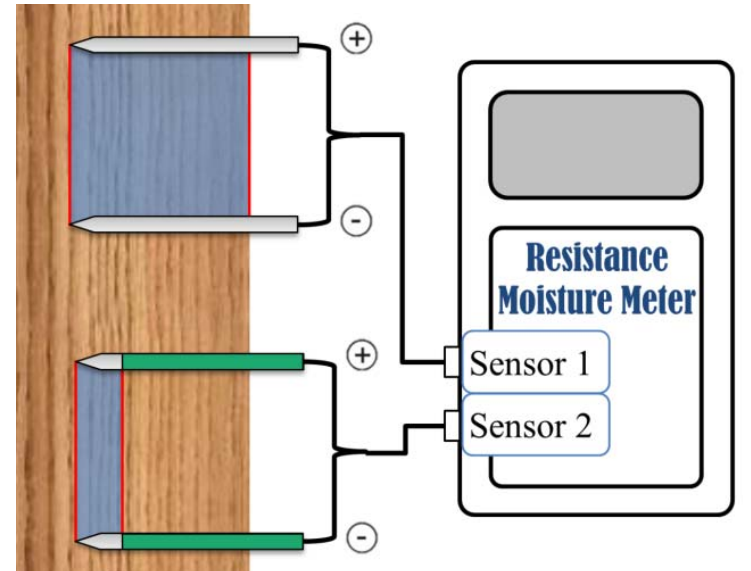

Fig. 9:Schematic of areas measured by resistance method using insulated and noninsulated electrodes

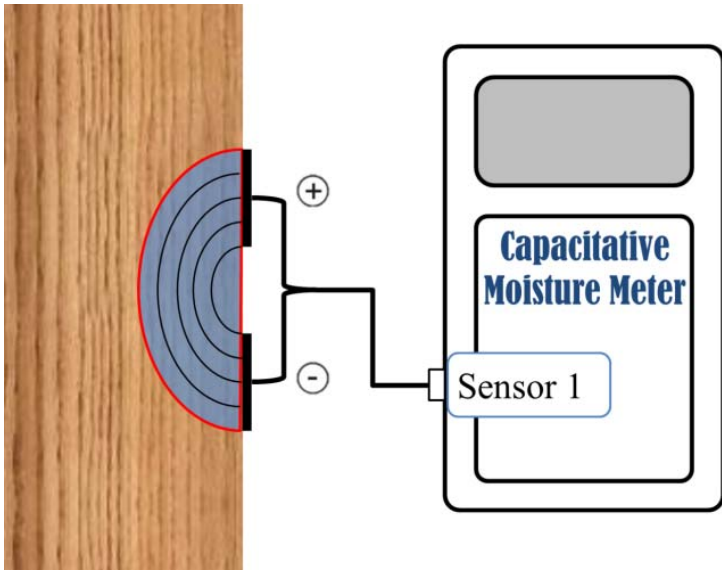

Fig. 10: Schematic of areas measured by capacitative method 


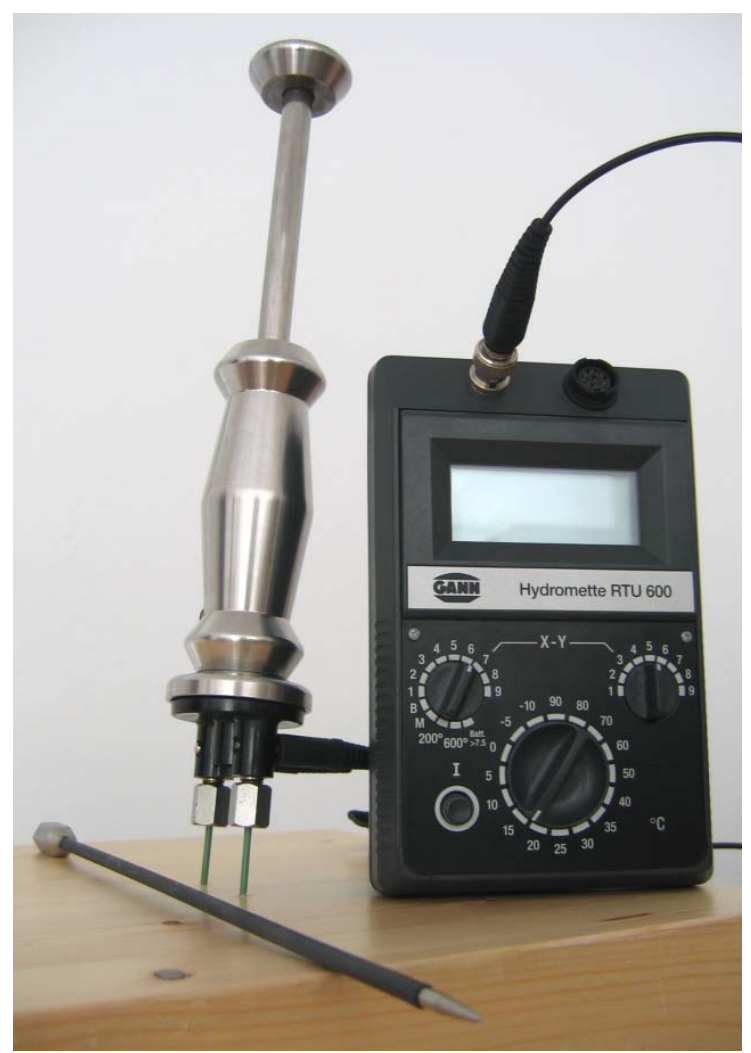

Fig. 11:Commercially available device using the resistance method

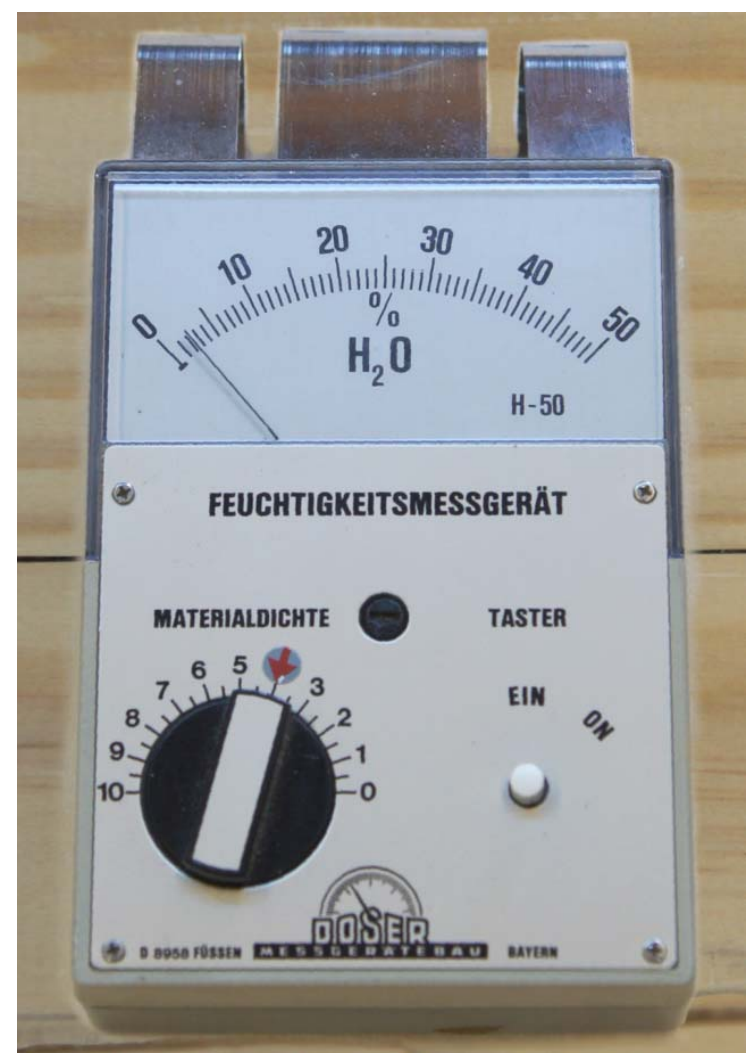

Fig. 12: Commercially available device using the capacitative method

\subsubsection{Microwave method}

The microwave method is comparable to the capacitative method but works at higher frequencies. It makes use of the effect that water molecules feature much higher absorption from microwaves than dry wood. This can be attributed to the different dielectric constants of water and wood. Reflection and absorption are indicators for the wood moisture content. Measurements are quite exact $( \pm 0,5 \%)$, material density and material temperature are the main influencing factors. The method is mainly used to measure moisture contents of wooden boards, wood based panels or chips, strands respectively flakes [2]. It is generally applicable for monitoring concepts but the comparably high cost of measurement equipment could currently impede its application.

\subsubsection{Sorption method}

The sorption isotherm describes the relationship between the ambient relative humidity and the equilibrium moisture content of a material. The relative humidity in a closed, air-filled cavity adapts to the material moisture content through the cavity walls. The relative humidity in the cavity can be measured and related to the material moisture content through its sorption isotherm. This method is generally applicable to timber elements since wood features a large specific surface, leading to a comparably faster equalization between relative humidity and wood moisture content [2]. The relative humidity is commonly measured by capacitative hygrometers which measure the change in the dielectric constant of a material between two condensator plates during water adsorption. Such hygrometers could be glued into the timber cross-section and isolated from the surroundings by rubber sealants, i.e. they are generally applicable for monitoring concepts. 


\subsubsection{Radiometric method}

Neutrons experience a deceleration when striking atoms. The deceleration caused by the $\mathrm{H}$-atoms in water is considerably higher than by the other elements contained in wood. The "slow" neutrons are registered by particular receivers, which only register neutron radiation [2]. The deceleration process can be measured and electronically evaluated with the aid of radiation-counter tubes. The measurements are highly dependent on the density of the material, necessitating the additional determination of the density of the timber specimen. This fact impedes the in-situ application of this method.

\subsubsection{Spectrometric method}

The spectrometric method is based on the capacity of water to absorb light of wave lengths $1930 \mathrm{~nm}$ and $1450 \mathrm{~nm}$. Moist wood will absorb more light than dry wood, i.e. dry wood will feature a higher reflection than moist wood [2]. The small penetration depth of the light waves only allows to measure moisture contents at the wood surface $(<0,1 \mathrm{~mm})$, making this method less applicable for in-situ measurements on structural timber elements.

\subsubsection{Colour-reaction method}

The wood moisture content is determined through an indicator paper which has been immersed in a chemical, e.g. cobalt chloride. A hole is drilled into the timber member. The indicator paper which is inserted in a drill hole in the timber member will change its colour in dependence of the wood moisture content. The method is applicable for wood moisture contents $6 \leq u \leq 20 \%$ and requires temperatures between $15^{\circ} \leq T \leq 25^{\circ} \mathrm{C}$ [2]. Abovementioned facts impede its application for monitoring concepts.

\section{Monitoring moisture content in timber elements}

\subsection{Requirements}

The implemented measurement method must fit a number of requirements. The measurement must take place without damaging the structure or taking samples. The accuracy of measurements must be consistent. The system must enable mounting on the structure itself and allow for independent measurements and digital logging of the results at different locations of measurement. Oftentimes the chosen measurement method must enable the determination of timber moisture content in different depths of the crosssections to derive a moisture gradient. The timber moisture content should be measured and recorded in equal time intervals (e.g. one hour). Typically it is also necessary to additionally measure climate data such as relative humidity, room temperature and material temperature at the location of moisture measurement. This necessitates data loggers to store the measured values. The system requires electricity, either in form of batteries or in form of direct power connection. The measurement system is required to function independently and reliably in different climates (cold/hot, dry/moist climate, condensation) and under different hazards (dirt and accidental contact/impact). Taking these requirements as well as the specific features of the methods presented in Chapter 2 into account, only a few applicable methods remain and have already found application in practice. These are explained in the following.

\subsection{Indirect monitoring of moisture content with the sorption method}

One indirect possibility to monitor moisture content is to apply the relationship between temperature + relative humidity and timber moisture content. The microclimate in the wood, i.e. temperature and relative humidity can be measured by transmitters which are 
usually applied to measure outside climate. These are glued into the timber cross-section and isolated from the surroundings by rubber sealants. The signals of the transmitter are collected by data loggers, see 3.5. This principle has been applied to monitor timber moisture content on bridges in Norway [16]. It is especially applicable in case of treated timber elements for which the known correlation between electrical resistance and moisture content (see below) is not valid anymore.

\subsection{Monitoring moisture content with the resistance method}

\subsubsection{General}

The electrical resistance method fulfills a multitude of above given requirements. It features an acceptable accuracy $( \pm 1,0 \%$ below $\mathrm{MC}=20 \%)$ as well as nearly nondestructive measurements. It enables measurements at multiple pairs of electrodes which are installed at different locations and/or which feature varying lengths. Due to these features, monitoring moisture content with the resistance method is a widely accepted and state-of-the art technique, commercially available in several variations see e.g. [16] - [27].

\subsubsection{Electrodes}

The electrodes used can feature nail-type (ram-in electrodes) or screw-type (screwed-in electrodes) geometry. They should be teflon-insulated to measure moisture content in clearly defined depths of the cross-section, see Fig. 9. To measure the timber moisture content in various depths, different types of electrodes at different lengths are available, see Fig. 13. The electrodes should be positioned in the same piece of timber (e.g. in the same lamella) and if possible perpendicular to the grain with a defined distance of usually $30 \mathrm{~mm}$ between them. To avoid interference between different points of measurement, each pair of electrodes should feature a sufficient distance to neighbouring electrodes (min. $150 \mathrm{~mm}$ ). For correct measurements, a permanent tight-fit is required between the electrode heads and the wood material. This can be realized by gluing-in the electrode or by pre-drilling with a diameter below the electrode diameter and re-drilling at reduced length with the electrode diameter before inserting and ramming in the electrode, see Fig. 14. In order to guarantee the same distances and depths for each drill hole without having to measure by hand, a drill guide can be very useful to simplify installation even at less accessible locations [17].

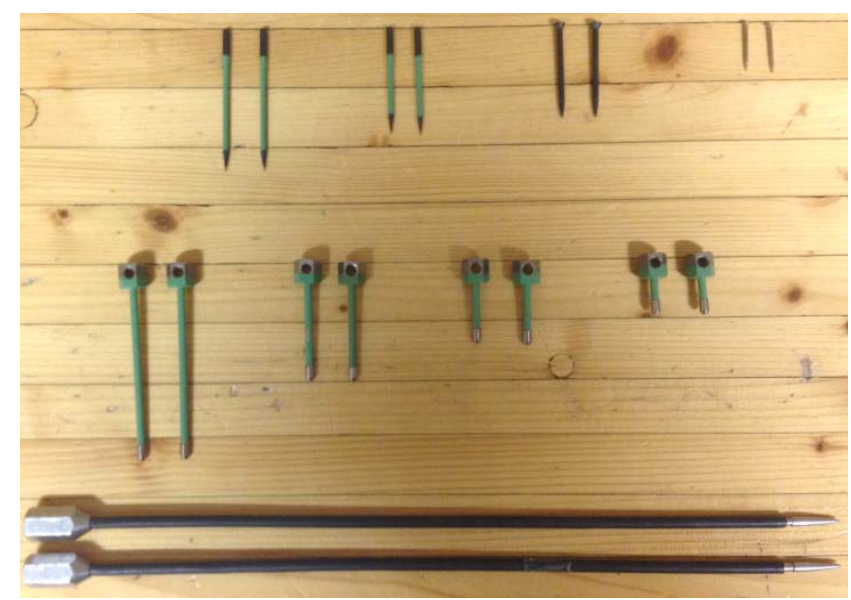

Fig. 13: Different types and lengths of insulated and non-insulated electrodes 


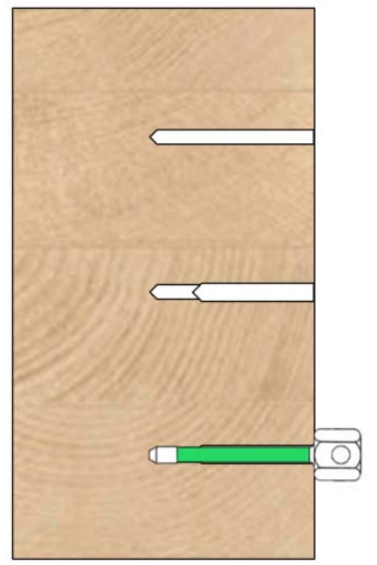

1. Pre-drilling with diameter below the electrode diameter until desired depth of ement

2. Re-drilling at reduced length with the electrode diameter

3. Inserting electrode and ramming in over remaining length

Fig. 14:Installation process to ensure tight fitting of electrode heads in the timber crosssection, from [17].

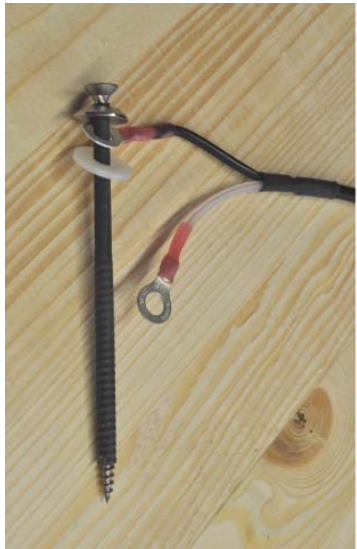

Fig. 15: Example for screw-type electrodes before installation and installed on-site, from [19]

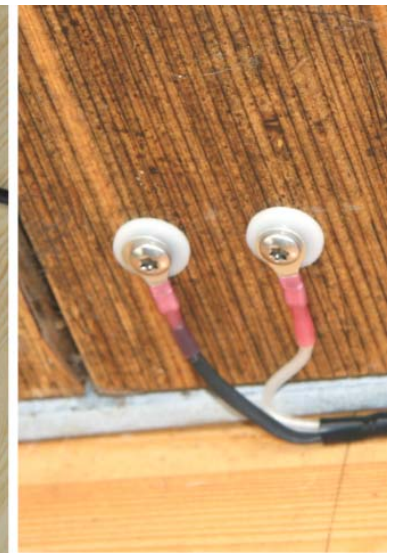

.

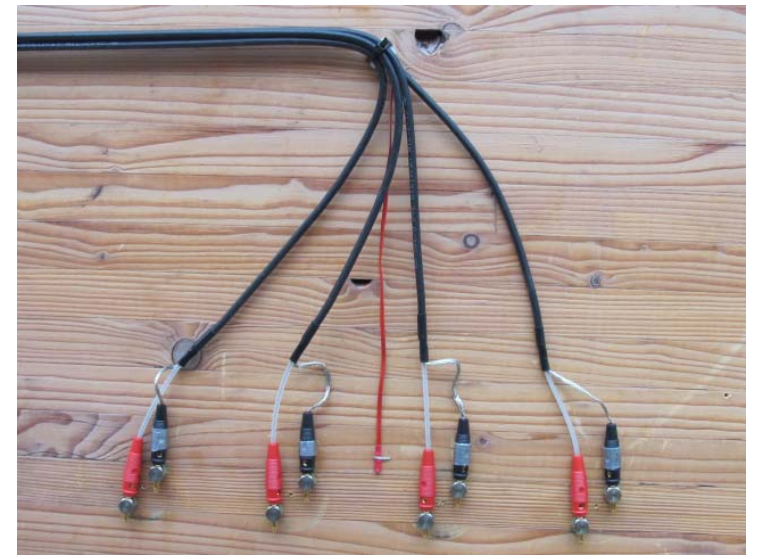

Fig. 16: Example of nail-type electrodes installed on-site

The electrodes are connected to the moisture meter by special shielded coaxial cables. The connections between the electrodes and the cables should be fully insulated to avoid shortcircuits in case of condensation around the point of measurement.

\subsubsection{Measurement system}

Applicable measurement systems must feature a very wide measuring range to determine moisture contents of dry and moist timber elements (e.g. $6 \% \mathrm{MC}$ in spruce $\approx 10^{11} \Omega$ ). The measurement system usually consists of a module with several channels to determine moisture content in materials at different locations and depths.

To prevent mutual interference, each channel is actuated and triggered successively but separately during measurement, allowing for independent measurement and subsequent transmission to a digital data logger. Power lines near the measurement system can lead to interferences and a temporary shifting of the measurements.

The system is usually expanded to additionally measure and store climate data such as relative humidity, room temperature and material temperature at the location of moisture measurement. The influence of material temperature on the timber moisture content should not be underestimated. The correlation is well established for temperatures between $10{ }^{\circ} \mathrm{C}$ and $40{ }^{\circ} \mathrm{C}$ [18]. In cases of rather constant surrounding climate, deriving the temperature in the cross-section from the surface temperature leads to plausible values with acceptable 
accuracy. In objects with strongly fluctuating surrounding climate it is advised to install temperature sensors within the cross-section at the depth of moisture measurement.

The commonly applied humidity sensors are based on measurements of the change in capacitance of a capacitor, e.g. a gold-plated special foil. Such sensors are not dew resistant which can lead to falsification of results in case of air containing chloride. Digital capacitance sensors are dew resistant and less sensitive to external influence.

To obtain a robust measurement system it should be aimed at reducing as much as possible connecting pieces, intermediate switches and other parts that are prone to interference or failure. The measurement equipment and data loggers should be stored in an installation box with silica gel bags to prevent negative influence from accidental contact/impact, climatic fluctuations or dirt.

Fig. 17 shows the schematic of a potential measurement system which has been changed and adapted throughout several research projects e.g. [17], [18].

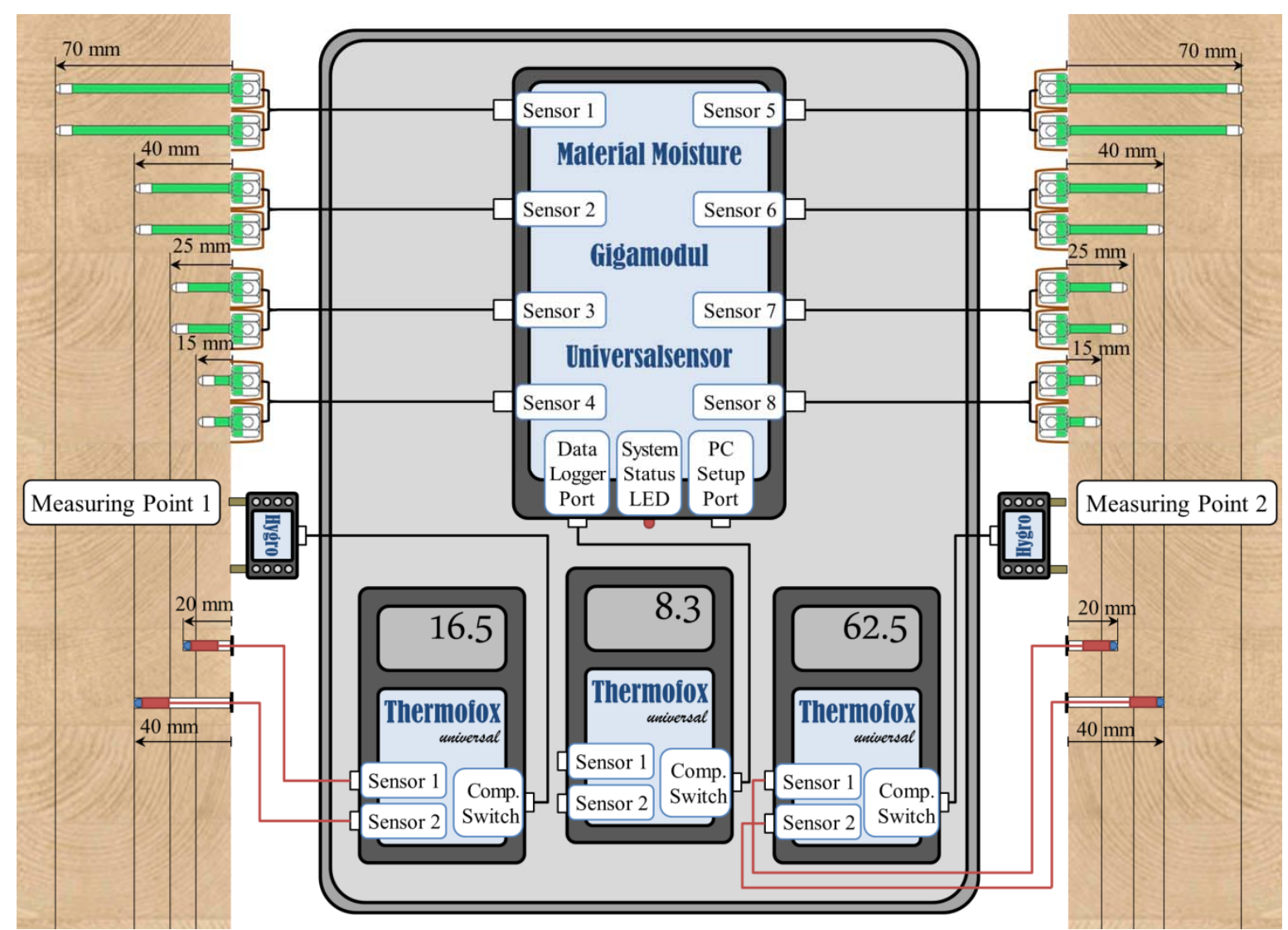

Fig. 17:Schematic of a potential measurement system based on the resistance method [18] 

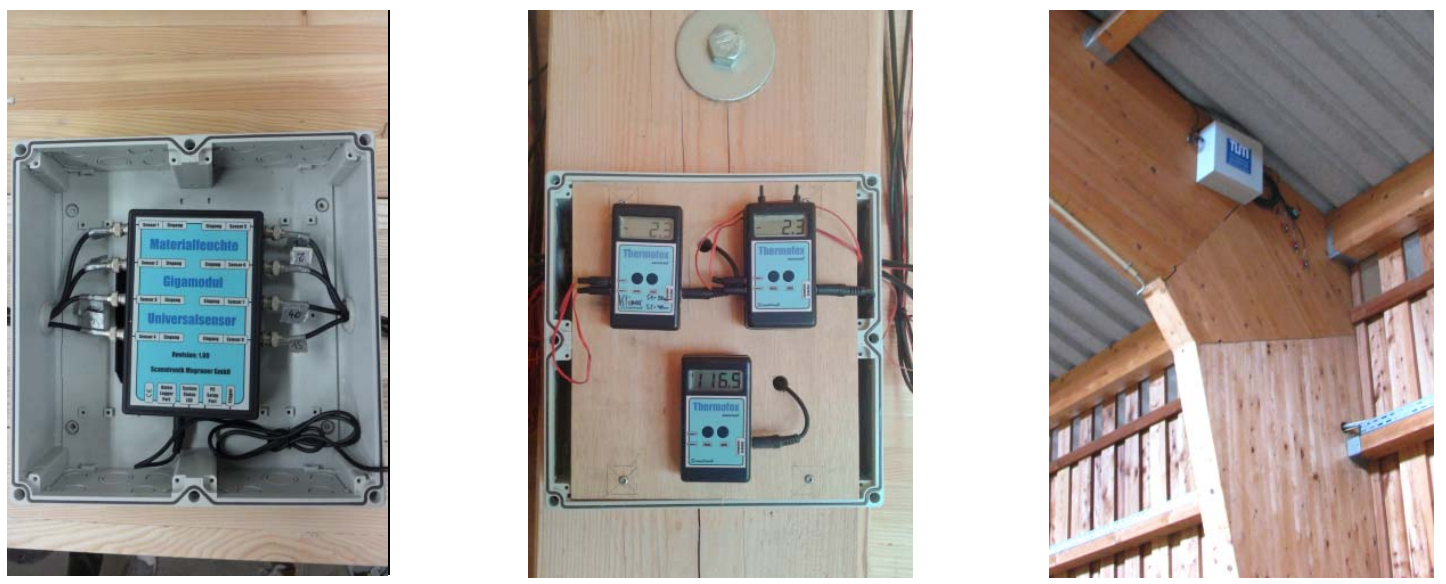

Figs. 18-20: Examples of measurement system installed on site, from [17], [18]

\subsection{Data loggers and remote transmission}

Data loggers must enable the storage of a large number of data in the range of ten thousands of data sets, according to the number of channels, frequency of measurement and length of period of continuous data logging. The data loggers should work according to the ring buffer principle, i.e. overwrite the oldest readings first when the memory is full. They should also enable the preservation of memory (measuring data) even when the electrical supply is cut off. Data loggers can be designed to enable a manual read out of the recorded data. This is commonly realized through a cable, e.g. a USB cable, enabling direct copying of data to a laptop. This necessitates on site accessibility and temporary demounting of the data loggers. Manual readouts imply regular and physical presence of personnel and travel to and from the object of measurement. The advantage however being, that they can be combined with a reference measurement with another moisture meter, a function control of the system as well as a control of the points of measurement and the structure itself.

Wireless retrieval of measurement data is commonly realized with data transmission system operating with a GPRS modem. Equipped with a SIM-card, these systems send the measurements stored in the data logger as e-mail attachments automatically and at preset intervals. Another option is to collect data through a telephone call to the transmission system. The latter necessitates much more electrical power since the system has to be on constant standby, i.e. it is advisable to use direct power supply instead of batteries in that case.

Commonly each part of the measurement system features self-sustaining power supply, mostly through batteries. The measurement system, climate sensors and data loggers use little energy, i.e. they can work for more than one year on a few batteries. Wireless data transmission systems use more energy, i.e. the transmission intervals should not be too short or the system should be connected to direct power supply. Some systems also transmit information on battery status. In this case, all parts of the measurement system should be powered by the same battery.

\subsection{Evaluation of data}

The raw data received from manual or remote readout is passed onto a program (e.g. spreadsheet program) for further processing. Here the resistance measurements are converted into actual values of timber moisture content taking into account the influence of temperature. Apart from data processing, the program should enable graphical illustration of the data in different charts. This enables better analysis of the data, e.g. visual checks 
with respect to unrealistic jumps in the values or detection of a damage occurrence in the structure, see Fig. 21. Useful graphical illustrations include curves (time series) of timber moisture content (in different depths, see Fig. 22), relative and absolute humidity and temperature, see e.g. [17] - [21]. Data on the building climate can be used to calculate the equilibrium moisture content to enable a better understanding of the correlation between the timber moisture content and the climatic boundary conditions. Additional useful graphs include the envelope curves of minimum and maximum timber moisture contents and timber moisture gradients, see e.g. [17] - [21].

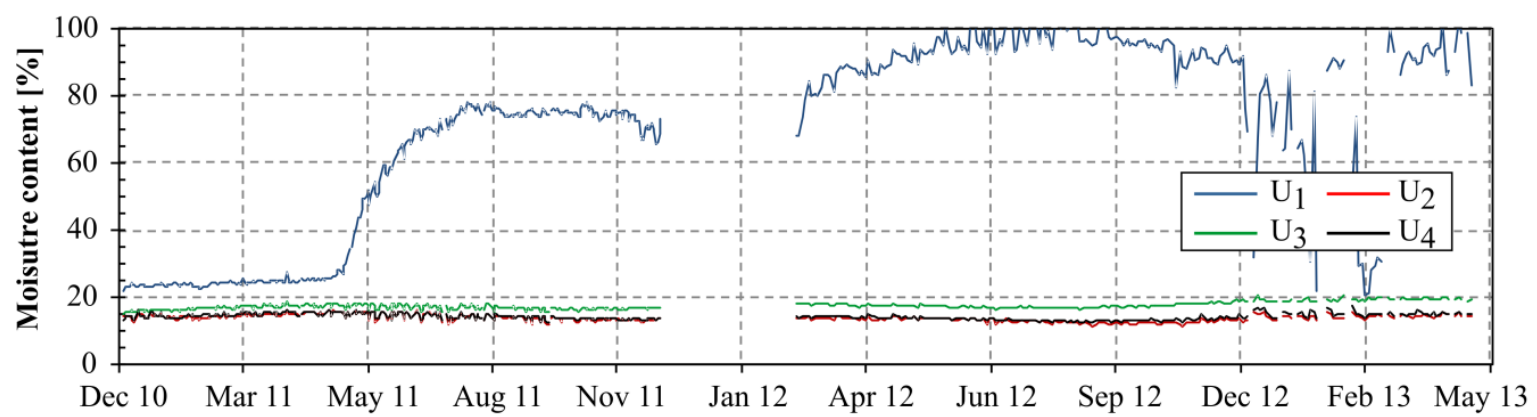

Fig. 21: Example of moisture data with a sudden increase at one sensor, from [21].

Timber moisture content at measuring point 1 (temperature compensated)

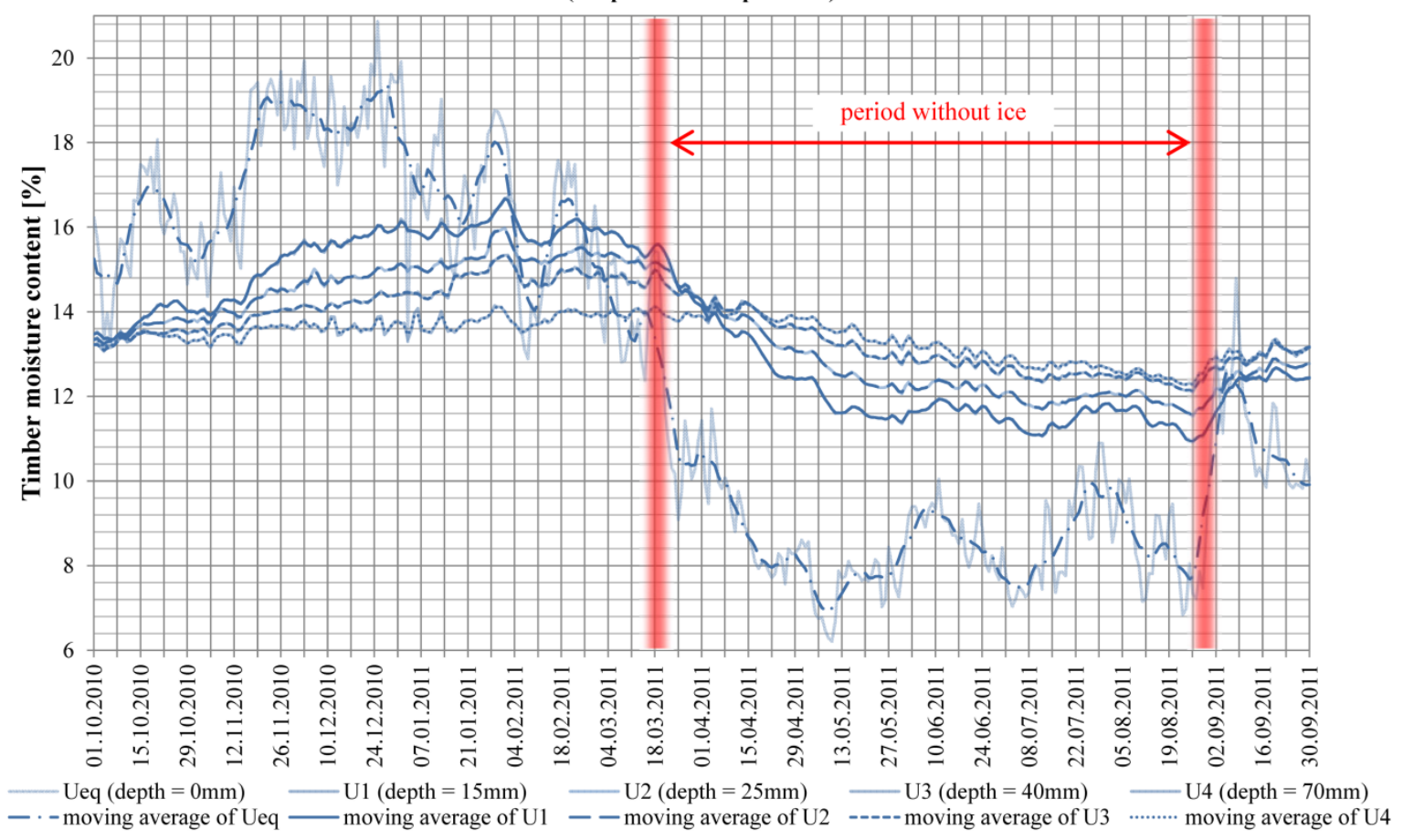

Fig. 22: Example of variation of timber moisture content at different depths of the crosssection in an ice-rink arena, from [20].

\subsection{Application and case studies}

For examples and case studies, the interested reader is referred to [20] and [21]. 


\section{Conclusion}

To ensure the safety of timber buildings over a long lifetime, it is important to secure design assumptions like dimensions, strength and stiffness properties and service classes. The moisture content of wood has a direct influence on the physical and mechanical properties but also on the risk of insect attack and fungal decay. In contrast to many other wood properties the wood moisture content can be measured and quantified, enabling a correlation of these values with numerous other wood properties. The monitoring of timber moisture content and/or the surrounding climate during use can therefore provide important parameters for the assessment of the current condition and/or the residual lifetime, helping to secure the expected performance of large span timber structures or timber bridges.

Different methods are known to measure wood moisture content; amongst which the electrical resistance method is the most common, as indicated by a large amount of projects and associated experience. This method delivers acceptable accuracy and enables easy application during single measurements as well as long term monitoring. The measured data can be stored locally or could be sent directly by a remote system for direct analysing and thus introducing the possibility of an early-warning system to detect possible damage. Even though there are many systems available, a general standard for the measuring and monitoring equipment has yet to be established. Several projects provide information on different systems that could be used depending on the particular situation. From the perspective of users and scientists, the available equipment could still be improved in terms of robustness and handling.

\section{Literature}

[1] Kollmann, F., Coté, W., A., Principles of Wood Science and Technology I: Solid Wood, Springer, Berlin, 1968.

[2] Niemz, P., Physik des Holzes und der Holzwerkstoffe, DRW-Verlag, Leinfelden-Echterdingen, 2003.

[3] Skaar, C., Wood-Water Relations, Springer, Berlin, 1988.

[4] Siau, J.F., Transport processes in wood, Springer, New York, 1984.

[5] EN 1995-1-1:2004, Eurocode 5: Design of Timber Structures - Part 1-1: General - Common rules and rules for buildings, European Committee for Standardization CEN, Brussels, Belgium, 2004.

[6] Hawley, L., F., Wood-liquid relations, Technical Bulletin Nr. 248, United States Department of Agriculture, Washington, D.C., 1931.

[7] Keylwerth, R., Einfache Kontrollmessung bei der Holztrocknung, Holz-Zentralblatt, Vol. 75, 1949, pp. 307-309.

[8] Stamm, A.J., Harris, E.E., Chemical processing of wood, Chem. Publ. Co. Inc., New York, 1953.

[9] EN 13183-1:2002, Moisture content of a piece of sawn timber - Part 1: Determination by oven dry method; European Committee for Standardization CEN, Brussels, Belgium, 2002.

[10] Villari, E. Annalen der Physik und Chemie - Untersuchungen über einige Eigenschaften des mit seinen Fasern parallel oder transversal durchschnittenen Holzes, Bd. CXXXIII, Leipzig, 1886.

[11] Keylwerth, R., Noack, D., Über den Einfluß höherer Temperaturen auf die elektrische Holzfeuchtigkeitsmessung nach dem Widerstandsprinzip, Holz als Roh- und Werkstoff, Vol. 14, No. 5, 1956, pp. 162-172.

[12] Ugolev, B. 1986. Holzkunde und Grundlagen der Holzwarenkunde, Lesnaja Prom, Moskau, 1986.

[13] Herrmann, M., Innovationen der Holzfeuchtemessung, Diploma Thesis, Chair for Timber Structures and Building Construction, Technische Universität München, 2009

[14] EN 13183-2:2002, Moisture content of a piece of sawn timber - Part 2: Estimation by electrical resistance method; European Committee for Standardization CEN, Brussels, Belgium, 2002.

[15] EN 13183-3:2005, Moisture content of a piece of sawn timber - Part 3: Estimation by capacitance method; European Committee for Standardization CEN, Brussels, Belgium, 2005. 
[16] Evans, F., Kleppe, O., Dyken, T., Monitoring of Timber Bridges in Norway - Results, Report, Norsk Treteknisk Institut Oslo, 2006.

[17] Gamper, A., Dietsch, P., Merk, M., Winter, S., Building Climate - Long-term measurements to determine the effect on the moisture gradient in timber structures, Final Report, Lehrstuhl für Holzbau und Baukonstruktion, Technische Universität München, 2012.

[18] Gamper, A., Dietsch, P., Merk, M., Winter, S., Building Climate - Validation of long-term measurements to determine the effect on the moisture gradient in timber structures, Final Report, Lehrstuhl für Holzbau und Baukonstruktion, Technische Universität München, 2014.

[19] Franke, B., Müller, A., Vogel, M., Tannert, T., Langzeitmessung der Holzfeuchte und Dimensionsänderung an Brücken aus blockverleimten Brettschichtholz, Research report, Bern University of Applied Sciences, Switzerland, 2012.

[20] Dietsch, P., Gamper, A., Merk, M., Winter, S., Monitoring building climate and timber moisture gradient in large-span timber structures, this issue.

[21] Franke, S., Franke, B., Müller, A., Case study - Long term monitoring of timber bridges, this issue.

[22] Franke, B., Widmann, R., Müller, A., Tannert, T., Assessment and monitoring of the moisture content of timber bridges, Proceedings International Conference on Timber Bridges 2013, Las Vegas, USA.

[23] Brischke, C., Rapp, A.O., Untersuchung des langfristigen Holzfeuchteverlaufs an ausgewählten Bauteilen der Fußgängerbrücke in Essing, Report Bundesforschungsanstalt für Forst- und Holzwirtschaft, Hamburg, 2007.

[24] Feldmeier, F., Ergebnisse und Schlussfolgerungen aus den Felduntersuchungen einer Eissporthalle, Proceedings „Ingenieurholzbau - Karlsruher Tage“, 2007, pp. 98-104.

[25] Fellmoser, P., Langzeitüberwachung von Holztragwerken, Proceedings „Ingenieurholzbau Karlsruher Tage“, 2012, pp. 77-87.

[26] Schäfer, W., Konsequenter Holzschutz macht's möglich - Grünbrücke Luckenwalde, Bauen mit Holz, No. 9, 2013, pp. 16-21.

[27] Brischke, C., Rapp, A.O., Bayerbach, R., Measurement system for long-term recording of wood moisture content with internal conductively glued electrodes, Building and Environment, Vol. 43, No. 10, 2008, pp. 1566-1574. 